\title{
FETAL HEAD MOLDING: AN INVESTIGATION UTILIZING A FINITE ELEMENT MODEL OF THE FETAL PARIETAL BONE*
}

\author{
Grego K. McPherson't \\ Bioengineering Program, University of Michigan, Ann Arbor, MI 48109, U.S.A. \\ and \\ TIMOTHY J. KRIEWALL + \\ Department of Obstetrics and Gynecology, University of Michigan, Ann Arbor, MI 48109, U.S.A.

\begin{abstract}
Abatract - Fetal head molding is the change in head shape due to the forces of labor. Previous investigations of the molding process have been largely qualitative in nature. In order to provide a first step toward a quantitative description of the deformations of the fetal head, a finite element analysis of the parietal bone of the fetal skull is performed. The structural geometry of the bone is derived from orthogonal radiographs of a full term anatomical specimen. Load and material parameters are taken from previous investigations. The bone is modeled using 63 thin shell elements from the SAP IV element library. Scaled models of preterm parietal bone are compared to term bone models.

The results indicate that the models undergo deformations which are qualitatively similar to those seen in normal labor. The preterm parietal bone model exhibits deformations $2-4$ times greater than the term bone model for the same load distribution. The significance of these results and their relationship to the molding process are discussed.
\end{abstract}

\section{INTRODUCTION}

Due to the forces of labor, the fetal head changes shape as it passes through the birth canal - a process termed "molding". Excessive molding has been implicated in conditions ranging in severity from subtle psychoneurological disorders to mental retardation, cerebral palsy and even death (Churchill, 1970; Glenting, 1970; Holland, 1922; Wigglesworth and Husemeyer, 1977; Willerman, $1970 \mathrm{a}, \mathrm{b}$ ). Yet, intrapartum diagnosis of excessive molding is beyond the capabilities of present day obstetrics.

There have been only a limited number of studies which have investigated the biomechanics of the molding process, and the majority of these have been qualitative in nature. In order to derive a quantitative understanding of the process, an approach is needed which is based on the classical analysis techniques of engineering mechanics. Viewing the fetal head as a complex biomechanical structure, the problem can be subdivided into three distinct areas: (1) deriving the mechanical properties of fetal cranial tissue, (2) deriving the structural configuration of the head, and (3) evaluating the loads of fetal head during labor. Preliminary information is available from previous investigations for both the pressure distributions on the fetal head during normal labor (Lindgren, 1960; Schwarcz et al., 1970) and the mechanical properties of

\footnotetext{
- Received 22 October 1978 ; in revised form 6 March 1979

+Present address: 3M Company, Surgical Products Division, St. Paul, MN 55101, U.S.A.

†Address reprint requests to Timothy J. Kriewall (Assistant Professor, Biomedical Engineering).
}

fetal cranial bone (McPherson and Kriewall, 1979). While various anatomical diameters of the fetal skull are readily available, the complex curvature of the surface of the skull has not been adequately described to date. Given that such a description can be developed, however, the information in each of these three areas can be used to synthesize a simplified mathematical model of the fetal skull using the method of finite element analysis. The structure of available, general-purpose finite element programs is such that a model is limited to "small strain" analysis. The results from such a simplified analysis point the way to more sophisticated analyses which are capable of incorporating the geometrical and material noniinearities inherent in a complete solution of the problem.

\section{BASIC MODELING GUIDELINES}

Because occiput transverse, vertex presentations constitute $\mathbf{7 5 - 8 0 \%}$ of all vaginal deliveries (Hellman and Pritchard, 1971), this presentation is used as the basis of this investigation. With the head in a transverse position and assuming a synclitic presentation (i.e. the sagittal suture is equidistant from the symphysis and the sacral promontoryl, the distribution of pressure on the head is symmetrical with respect to the sagittal plane. The conditions of symmetry permits simplification of the model.

The fetal skull consists of four regions: (1) the face/base region, (2) the frontal bones, (3) the parietal bones, and (4) the occipital bone. The face/base region consists of well-ossified bones and (in comparison with the cranium) is relatively rigid. This region can there- 
fore be neglected in molding studies. It has also been demonstrated that the occipital bone is relatively rigid and displacements of the bone are limited to rotations of the bone about the occipital hinge (Moloy, 1942). While the frontal bones and occipital bone do contribute to the overall response, the largest amount of distortion seems to take place within the parietal bones. The increased curvature and elevation of the vertex seen in studies such as those described by Borell and Fernstrom (1958a, b) appear to be largely due to the deformations within these bones.

In view of the foregoing, the initial modeling was confined to the parietal bones. This allowed an analysis of the deformation response uncomplicated by the effects of the underlying brain, the septa of the dura mater and the membranous sutures.

Another aspect of this modeling effort was to investigate the differences in response between preterm and term bone. Premature birth is the most significant factor in neonatal death (Hellman and Pritchard, 1971). Increased deformations of the preterm skull, as compared to the term skull, due to the pressures of labor could be an important contributor to this neonatal loss.

\section{STRUCTURAL GEOMETRY AND MODELING}

To investigate the deformation response of the fetal skull, the geometry of the skull first must be quantified. Because the skull has a complex irregular shape, traditional methods of measurement are unsuitable for accurately describing the surface geometry. The approach used in this investigation utilizes 3 orthogonal radiographs of a full-term anatomical specimen (Fig. 1). A full-scale drawing of the fetal skull was constructed from these radiographs using orthographic projections (Fig. 2).
The surface geometry of the preterm skull is assumed to correspond to that of the term skull with the overall dimensions reduced to representative values for a gestational age of 24 weeks. Data from Scammon and Calkins (1929) indicate that an overall scale reduction of 0.6 yields an accurate representation of the skull of the preterm fetus.

Because of the symmetry conditions mentioned previously, it is necessary to model only one of the parietal bones. The left parietal bone of both the term and preterm fetus is modeled using 63 thin shell elements as shown in Fig. 3. This element is a quadrilateral formed from four compatible triangles. The membrane and bending behavior are obtained from the Constant Strain Triangle and a conforming quadrilateral plate element (LCCT9), respectively. The quadrilateral has 6 degrees of freedom per node in the global coordinate system. The element is a standard library element in the SAP IV structural analysis program (Bathe et al., 1974).

Element node locations were chosen from both anatomical and structural analysis viewpoints. Certain locations such as the parietal eminence and the corners of the bone margins are natural node locations. The other node locations were chosen to best represent the curvature of the skull surface and also to minimize the element aspect ratio. The choice of this structural grid also allows the radial nature of the bone fibers (which are characteristic of fetal parietal bone) to be modeled conveniently. Preliminary investigations using other grid configurations established that the grid shown in Fig. 3 is the coarsest grid which allows a reasonable approximation to the geometry of the bone. The geometry chosen is representative of normal anatomy.

The decreasing bone thickness from the eminence to the margins is incorporated into the model by decrementing the element thickness in the three concentric

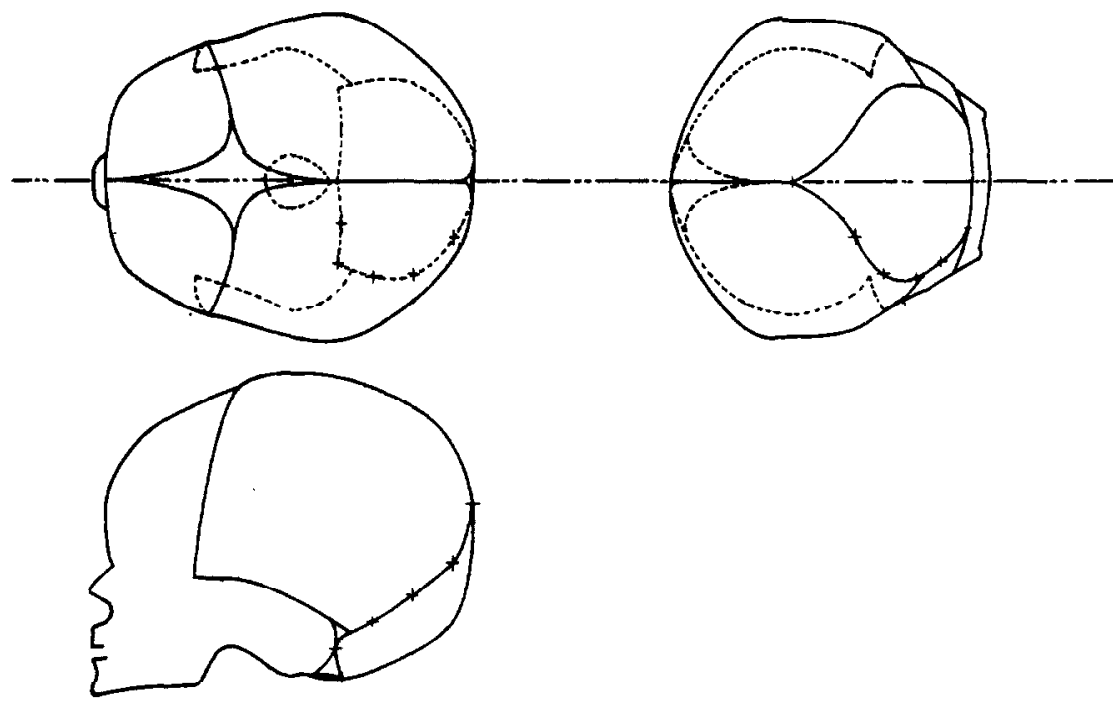

Fig. 2. Orthogonal drawing of the skull of a term fetus prepared using the radiographs shown in Fig. 1. 


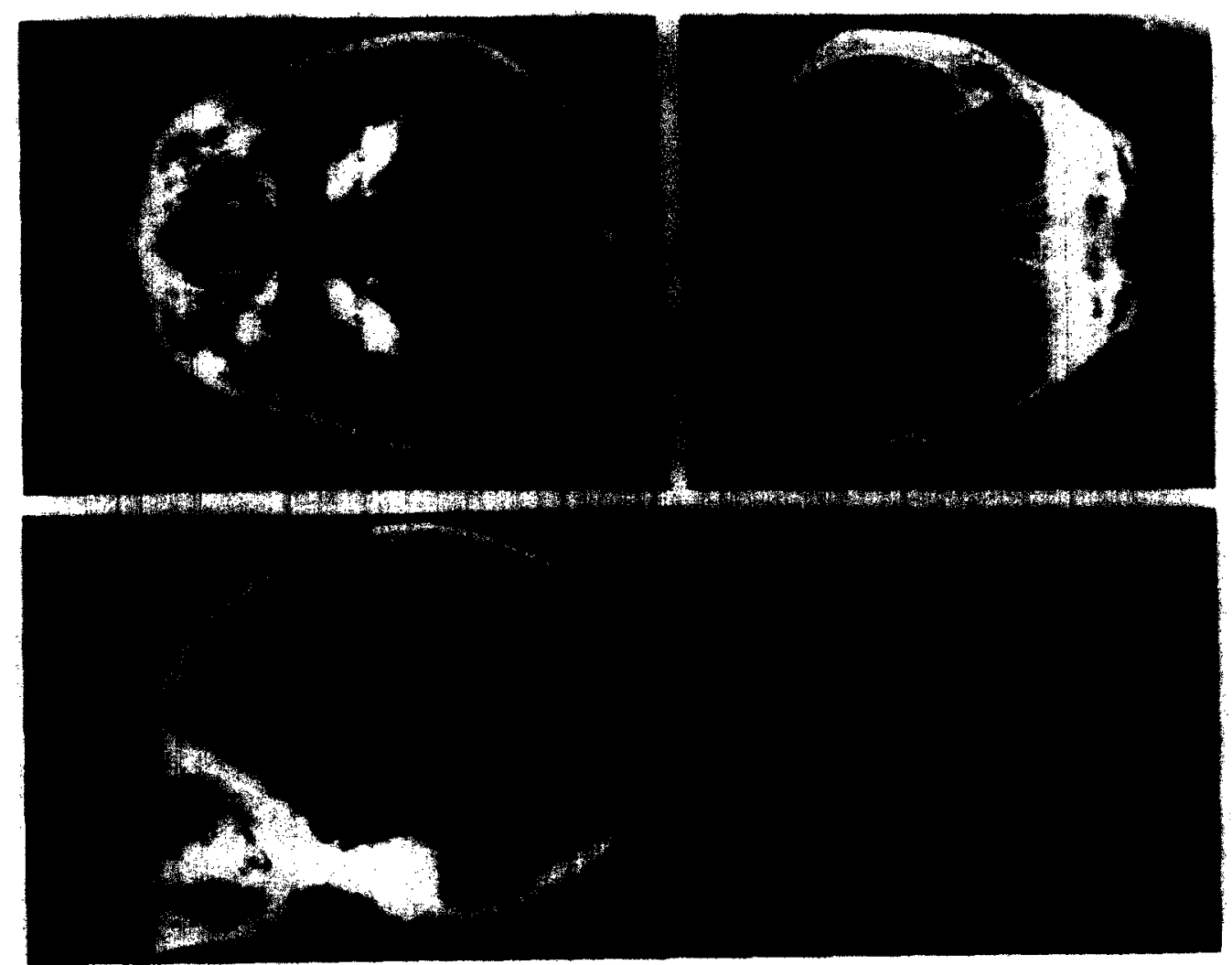

Fig. 1. Orthogonal radiographs of the skull from a term fetus used to quantify fetal head geometry. 


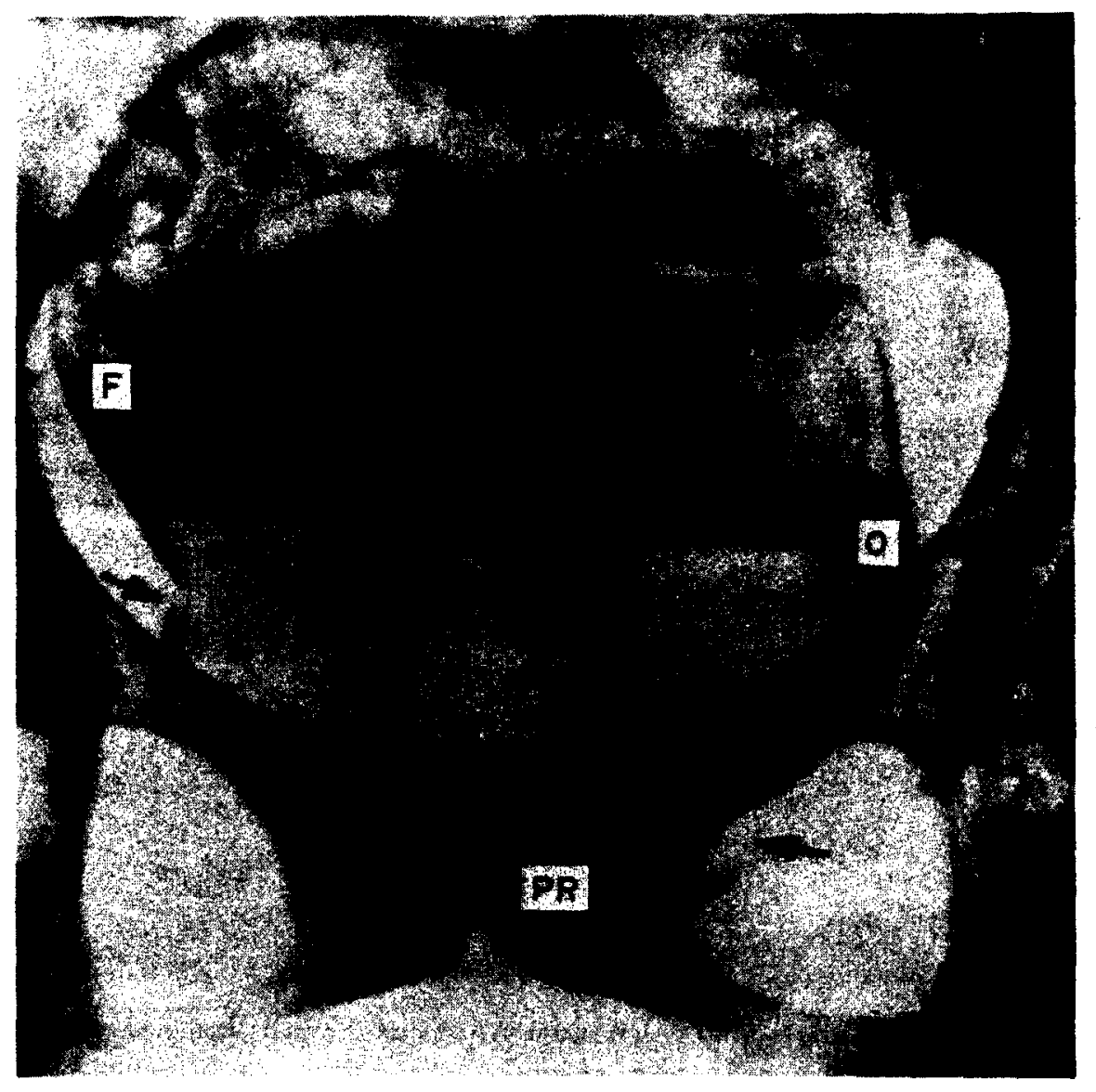

Fig. 9. Displacement of parietal bone during labor. Note the misalignment between the margins of the bones at the coronal and lamboidal sutures. (From Borell and Fernstrom, 1958a.) 


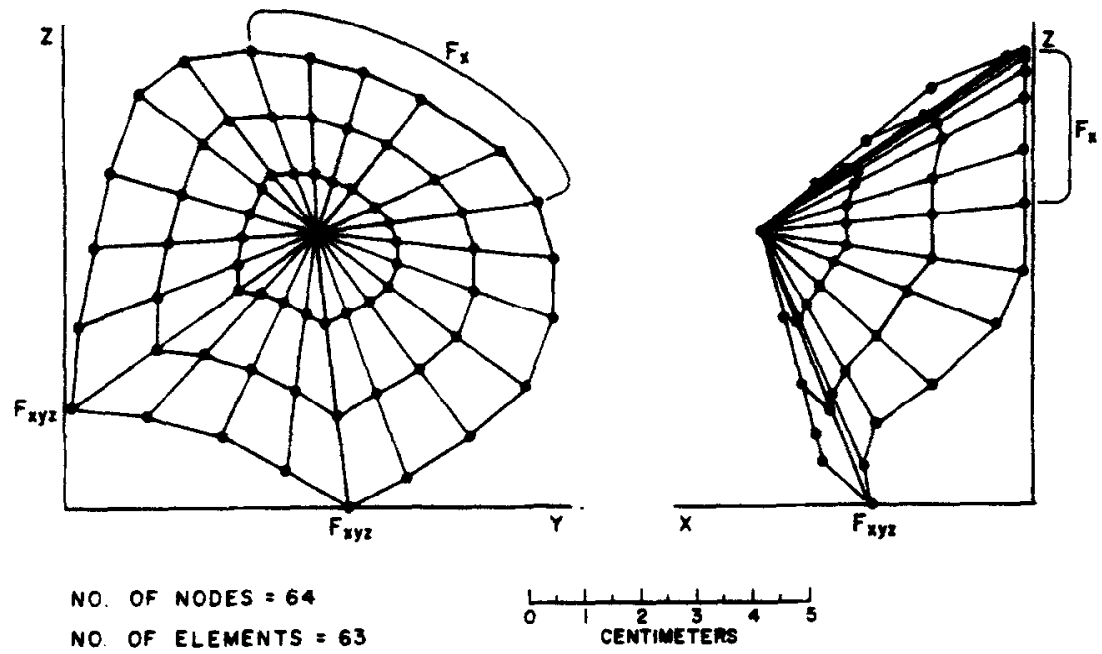

Fig. 3. Finite element model of a fetal parietal bone. $F_{x y z}$ denotes a node with displacements constrained in all directions; $F_{x}$ denotes a node with a constrained displacement in the $X$-axis while movement is permitted in the $Y-Z$ plane.

Table 1. Bone thickness values for elements of the fetal parietal bone model

\begin{tabular}{|c|c|c|}
\hline \multirow[b]{2}{*}{ Element group } & \multicolumn{2}{|c|}{ Element thickness (mm) } \\
\hline & Preterm & Term \\
\hline Inner ring & 0.61 & 0.89 \\
\hline Middle ring & 0.48 & 0.74 \\
\hline Outer ring & 0.36 & 0.61 \\
\hline
\end{tabular}

rings of elements. Bone thickness values used in both the term and preterm models (listed in Table 1) are constant within any one ring. They are based on the data derived in a previous investigation (McPherson and Kriewall, 1979).

The boundary conditions used in the model are chosen to remove rigid body displacements and to satisfy the requirements of symmetry. The node at each lower corner of the model is fixed with regard to displacement, but rotations about the $Y$-axis are permitted (Fig. 3). Nodes in the $Y-Z$ plane along the upper margin of the bone are required to stay within that plane ( $X$-displacement constrained), but can translate or rotate within the plane as the solution dictates. These boundary conditions were chosen to prevent the parietal bone model from rotating across the sagittal plane and hence "overlapping" the other parietal bone of the skull - a condition which never occurs in the live fetus (Borell and Fernstrom, 1958a).

\section{MATERIAL PROPERTIES}

Material property data are taken from an earlier investigation of the three-point bending response of small beam specimens of fetal parietal bone (McPherson and Kriewall, 1979). Values for the elastic moduli, both parallel and perpendicular to the bone fiber direction, were obtained in that study from the initial linear region of the load-deflection curves. The material parameters are thus limited to small strains.

Designating the $r$ direction as that parallel to the bone fiber and the $t$ direction as that perpendicular to the bone fiber, the mean moduli values for a term fetus are

$$
\begin{aligned}
& E_{r}=3.86 \times 10^{3} \mathrm{MPa} \\
& E_{t}=9.65 \times 10^{2} \mathrm{MPa} .
\end{aligned}
$$

From the data, fetal skull bone can be seen to be an orthotropic material, but because the fetal skull is thin in comparison to its external diameters, a state of plane streas may be assumed. The constitutive equation for plane stress is written in matrix form as

$$
\left\{\begin{array}{l}
\sigma_{r} \\
\sigma_{1} \\
\tau_{n}
\end{array}\right\}=\left[\begin{array}{lll}
c_{11} & c_{12} & 0 \\
c_{21} & c_{22} & 0 \\
0 & 0 & c_{3}
\end{array}\right]\left\{\begin{array}{l}
\sigma_{r} \\
\gamma_{n} \\
\gamma_{n}
\end{array}\right\},
$$

where $\sigma=$ normal stress; $\tau=$ shear stress; $\varepsilon=$ normal strain; $\gamma=$ shear strain; and $c_{i j}=$ constants. The constants $c_{i j}$ are given by:

$$
\begin{gathered}
C_{11}=\frac{E_{r}}{1-v_{r r} v_{t r}}=\frac{E_{r}}{1-v_{r t} v_{t r}} \\
C_{22}=\frac{E_{t}}{1-v_{r t} v_{t r}} \\
C_{12}=\frac{E_{r} v_{t r}}{1-v_{r m} v_{t r}} \\
C_{21}=\frac{E_{t} v_{t r}}{1-v_{r t} v_{t r}} \\
C_{33}=G_{r t}
\end{gathered}
$$

where

$E_{r}=$ elastic modulus in the $r$-direction (MPa), 
$E_{t}=$ elastic modulus in the $t$-direction (MPa),

$v_{n}=$ Poisson's ratio for load in the r-direction with lateral contraction in the $t$-direction,

$v_{t r}=$ Poisson's ratio for load in the $t$-direction with lateral contraction in the $r$-direction,

$G_{r t}=$ shear modulus $(\mathrm{MPa})$.

Using symmetry arguments, it can be shown that

$$
C_{12}=C_{21}
$$

and hence

$$
\frac{E_{r}}{v_{r t}}=\frac{E_{t}}{v_{t r}} .
$$

No data are available for Poisson's ratio, $v_{r m}$ in fetal bone, but McElhaney et al. (1970) report a value of 0.28 for adult cortical cranial bone. Assuming this value for fetal cranial bone, equation (8) implies that $v_{n}$ is approximately equal to 0.08 for term bone, while the value for preterm bone is approximately 0.03 .

The shear modulus, $G_{n}$, is also unavailable, but for isotropic materials:

$$
G=E / 2(1+v)
$$

Assuming that $E$ and $v$ in equation (9) may be approximated by $E_{r}$ and $v_{n}$, respectively, a value for $G_{n}$ may be calculated. Substituting the appropriate values into equations (2)-(6), the mean material parameters for the constitutive matrix may be derived. They are listed in Table 2.

\section{LOADING DATA}

Lindgren (1960) used a series of small pressure transducers inserted between the uterus and the fetal membranes enclosing the fetal head to monitor pressures. These transducers were spaced so as to measure amniotic pressure as well as three intrapelvic pressures along the head. In the first stage of labor, Lindgren found the pressure at the largest circumference of the head to be 3-4 times greater than the corresponding amniotic pressure. The pressure progressively diminished between the largest diameter and the vertex of the head. He hypothesized that it is this difference in pressure which provides the driving force for the characteristic shape changes of the fetal head.

Schwarcz et al. (1970) substantiated Lindgren's findings, but they noted that the ratio of the pressure at the largest circumference to the amniotic pressure was lower by a factor of two than the values quoted by Lindgren. They hypothesized that this difference was

Table 2. Material parameters for term and preterm fetal cranial bone assuming a state of plane stress

\begin{tabular}{lcccc}
\hline & \multicolumn{4}{c}{ Material parameters $\times 10^{-3} \mathrm{MPa}$} \\
& $C_{11}$ & $C_{12}$ & $C_{22}$ & $C_{33}$ \\
\hline Preterm & 1.67 & 0.04 & 0.14 & 0.63 \\
Term & 3.96 & 0.30 & 0.99 & 1.48 \\
\hline
\end{tabular}

due to the different types of pressure transducers used in the respective studies.

Bell (1972) extensively analyzed the pressure distribution of the fetal head interacting with the cervix during the first stage of labor. He assumed the head was a rigid sphere acted upon by a radial contact pressure from the walls of the cervix and also by a hydrostatic pressure due to the amniotic fluid. In a theoretical development, he calculated the magnitude of the pressure distribution on the fetal skull. Bell's analysis is used in this study as the basis for determining the loads because it provides the only known estimate of the distribution of pressure over the entire head. Equally as important, Bell's analysis allows the distribution and magnitude of the pressure to be calculated as a function of dilatation.

Assuming a variation in pressure of the form

$$
P_{n}=C r^{2} \text {, }
$$

the equilibrium of forces equation yields the relationship between amniotic pressure and the radial contact pressure

$$
\frac{P_{n}}{P_{a}}=\frac{2 R^{2} r^{2}}{R^{4}-r_{0}^{4}}
$$

where

$P_{n}=$ radial contact pressure,

$P_{a}=$ amniotic pressure,

$R=$ radius of the fetal head at the equator,

$r_{0}=$ radius of the cervical os,

$r=$ minor radius of the fetal head.

In order to more easily compare the response of the model at increasing degrees of dilatation, a constant amniotic pressure at $50 \mathrm{~mm} \mathrm{Hg}$ is assumed.

Using $5 \mathrm{~cm}$ as the radius for the fetal head, equation (11) can be solved for the radial contact pressure as a function of cervical dilatation.

The pressure at the largest diameter of the fetal head is relatively constant for dilatations of $40 \%$ or less, but increases as dilatation progresses. The calculated pressure distribution shows good agreement with the experimental results of Lindgren and Schwarcz et al. for dilatation of $75 \%$ or less.

Below the suboccipitobregmatic plane (see Fig. 4), where the cervix is in contact with the fetal head, the loads applied to the model of the parietal bone are those calculated using Bell's analysis. Above this plane, the cervix is no longer in contact with the head and the normal pressure equals the amniotic pressure.

Loads in the case of the preterm skull are calculated in exactly the same manner as in the term skull, using a radius for the preterm skull of $3 \mathrm{~cm}$.

\section{RESULTS}

The finite element model of the term parietal bone was analyzed for four different pressure distributions. These distributions corresponded to the case of hydrostatic pressure (present before engagement of the 


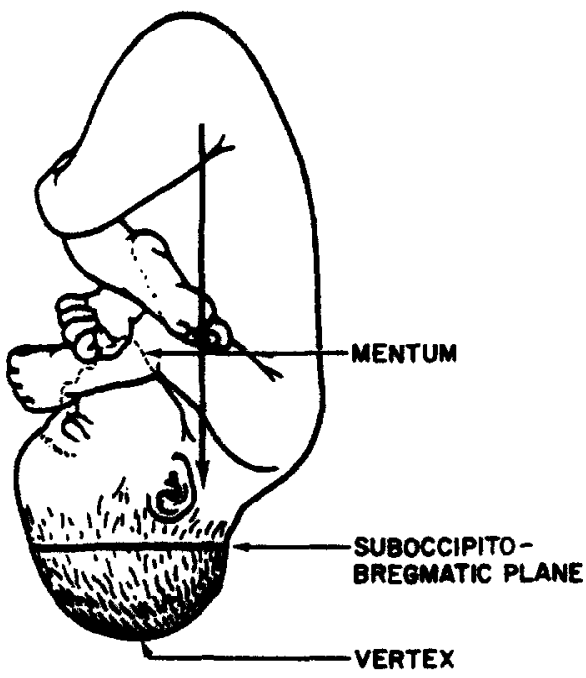

Fig. 4. The well-flexed head of a fetus is shown diagrammatically as it is positioned in most delivery presentations. Above the suboccipitobregmatic plane, only amniotic fluid is in contact with the head, so the pressure above the plane on the head equals the amniotic fluid pressure. From the suboccipitobregmatic plane towards the vertex, the head is in contact with the cervix. The pressure below the plane varies as a function of both the state of dilatation and where on the head the pressure is calculated. Beyond the cervical os, the relative pressure falls to zero.

head) and to degrees of cervical dilatation of 25,50 and $75 \%$. In addition, the preterm parietal bone model was analyzed for a pressure distribution corresponding to $50 \%$ cervical dilatation.

In order to more easily assess bone distortions under the applied loads, three linear measurements of deformation were calculated for each load case. These "strains" were defined as the ratio in chord length change connecting two points on opposite margins of the bone to the initial chord length (Fig. 5). Three chords were used : (1) the chord joining the midpoints of the anterior and posterior margins of the bones; (2) the chord joining the midpoints of the superior and inferior margins of the bone; and (3) the chord joining the parietal eminences of the two sides of the head (the biparietal diameter). The change in length of each chord was determined from the calculated displacement of the nodes at each end of the chord. The results for the term parietal bone model are plotted in Fig. 6.

Several observations are apparent. First, some distortion of the parietal bone is present before engagement due to the hydrostatic pressure distribution of the amniotic fluid. After engagement, and as dilatation progresses, the deformation of the bone increases in an exponential manner. The mentovertical chord increases in length while the other two chords decrease. For a dilatation of $75 \%$ or less, the magnitude of the decrease in the anteroposterior chord is larger than the magnitude of the increase in the other two chords. A comparison of the magnitude of the strains for the preterm and term parietal bones at a given level of dilatation reveals that the strains are approximately 2-4 times greater in the premature bone than in the term bone (Table 3 ).

Two orthographic drawings of the term parietal bone were prepared to depict the deformations as they appear superimposed on the undeformed skull (Figs. 7 and 8 ).

These figures represent the cases of hydrostatic pressure and $50 \%$ dilatation, respectively. The figures also incorporate a graphical representation of the respective pressure distributions.

The SAP IV structural analysis program provides, in addition to the node displacements, data on the resultant membrane stress and bending moment components for each element. The membrane stresses were usually larger (by $50-100 \%$ ) in the preterm model than those in the term bone model, while the opposite was true for the bending moments. Differences in magnitude varied from element to element, however. The maximum membrane stress never exceeded $5.5 \mathrm{MPa}$, while the maximum bending moment was always less

Table 3. Comparison of diametral strains for preterm and term parietal bone model

\begin{tabular}{lccc}
\hline $\begin{array}{c}\text { Gestational } \\
\text { age }\end{array}$ & $\varepsilon_{1}$ & $\varepsilon_{2}$ & $\varepsilon_{3}$ \\
\hline Preterm & -0.0299 & 0.0278 & -0.0295 \\
Term & -0.0133 & 0.0100 & -0.0104 \\
\hline
\end{tabular}

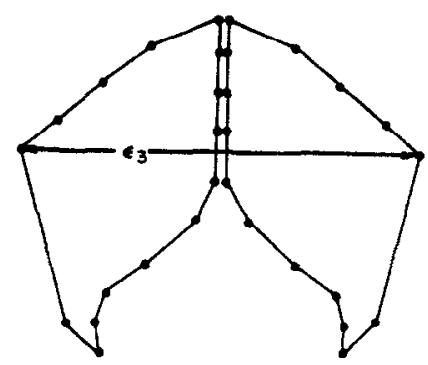

Fig. 5. Diametral strains used to define bone distortion. 


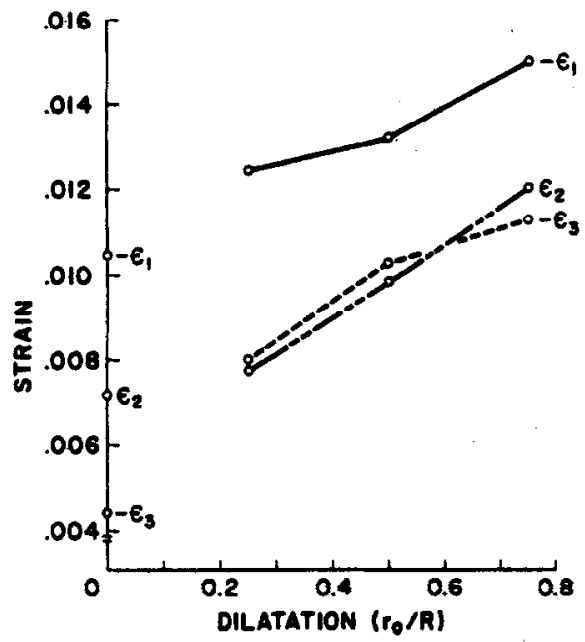

Fig. 6. Mean diametral strains for the term parietal bone as a function of dilatation. $\varepsilon_{1}$, anteroposterior strain; $\varepsilon_{2}$, vertical strain; $\varepsilon_{3}$, transverse strain.

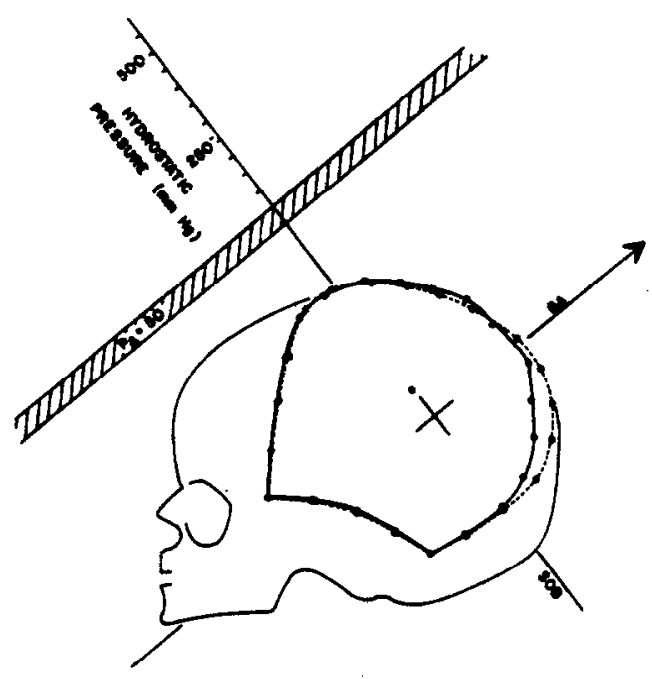

than 0.1 MPa. These results support the use of the linear finite element analysis program which assumes a condition of "small strain".

\section{Discussion}

One of the basic questions regarding molding is "How do the bony plates of the fetal skull influence the overall molding process? ? $^{n}$ Do they move as rigid structures with no deformation or, at the opposite extreme, do they simply deform (with no rigid-body displacement) around their initial position? While previous investigators have attempted to qualitatively describe the deformations of the parietal bones, this investigation is the first attempt to provide a method for quantitative description. Using the approach of mathematical modeling, it is possible not only to define linear measures unavailable to previous investigators, but more importantly, it is possible to analytically control those variables which would be

Fig. 7. Deformation of the term parietal bone model for the case of hydrostatic pressure. Deformations are shown twice normal size for clarity. SOB, suboccipitobregmatic plane; BA, axis of birth canal.
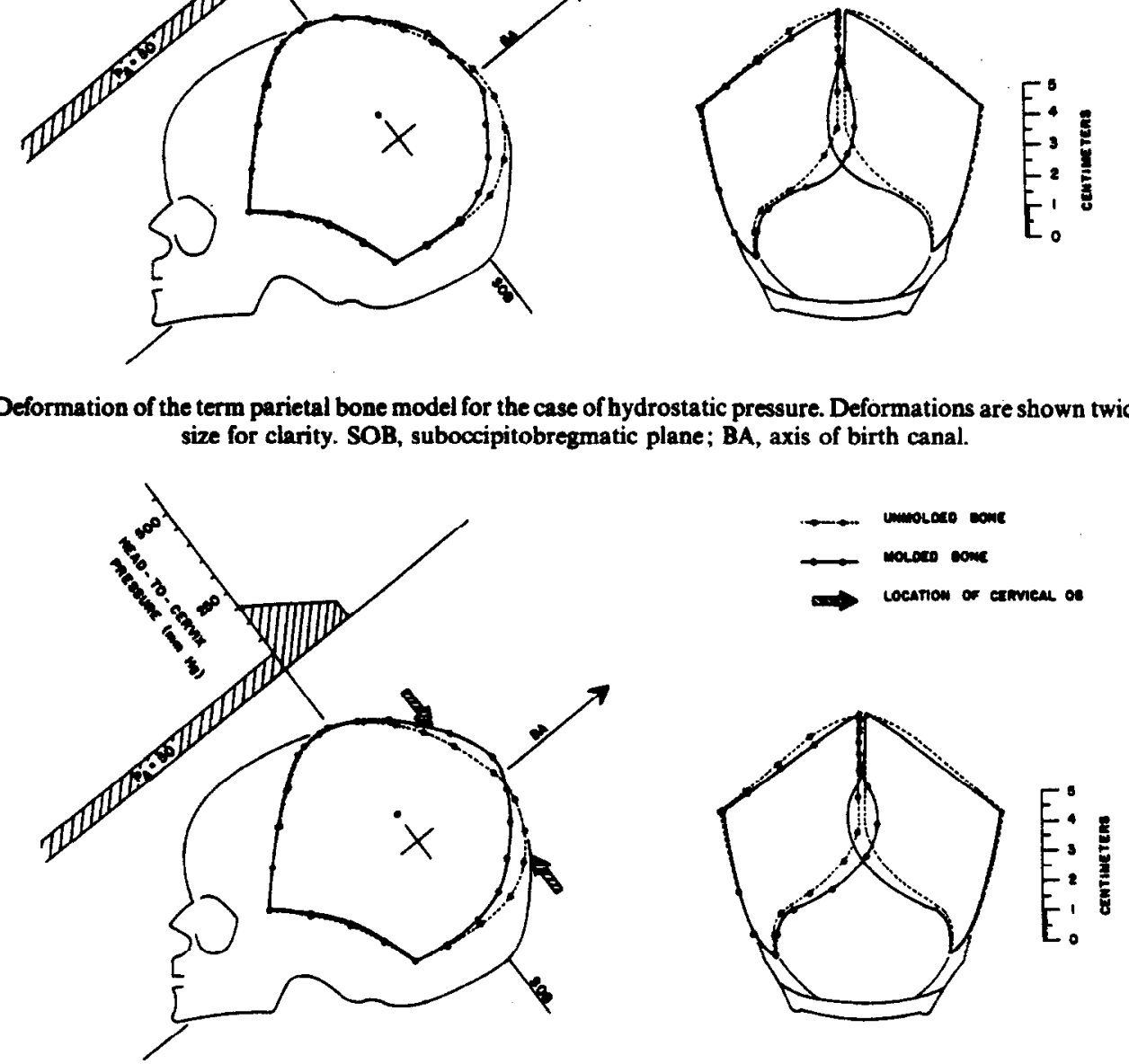

Fig. 8. Deformation of the term parietal bone model for the case of $50 \%$ cervical dilatation. Deformations are shown twice normal size. SOB, suboccipitobregmatic plane; BA, axis of birth canal. 
difficult or impossible to control under experimental conditions.

The analysis includes many simplifications and approximations which are made in order to create an initial model of the parietal bone. Small strain material parameters, linear finite element theory and calculated pressure distributions all tend to limit the range of deformations which are presently analyzable. Nevertheless, the results indicate that any effort to describe the molding process must account for deformation within the skull bones.

The ultimate test of any model, of course, is its correspondence to reality. Many of the results of this modeling study agree qualitatively with the results of previous investigators. Before labor ensues, Kriewall et al. (1977) found that the antepartum hydrostatic forces of Braxton-Hicks contractions shortens the mentovertical diameter. This is seen in Fig. 7. Figure 8 shows that, as dilatation progresses, the parietal bone shortens in its anteroposterior dimension while the vertex elevates. This is in agreement with the previous findings of Borell and Fernstrom (1958a). The elevation of the vertex causes an apparent displacement between the frontal and parietal bones and between the occipital and parietal bones when the head is viewed from the side - a displacement easily seen on skull radiographs taken during labor (Fig. 9). This misalignment is evident, furthermore, even when displacement in the frontal and occipital bones are ignored, as is the case in this investigation. This misalignment between the bones raises questions regarding the qualitative description of previous investigators (Moloy, 1942; Baxter, 1946). These investigators contend that the misalignment is at least partially an indication of the inward displacement of the frontal and occipital bones. Our investigation has demonstrated, however, that this does not have to be the case. Misalignment can occur through deformations of the parietal bones alone. Future investigations are required to assess the contributions of the frontal and occipital bones to the overall molding process.

The thinner, more flexible preterm parietal bone has been shown to be capable of undergoing larger deformation than term parietal bone under the same applied pressures. This may be a contributing factor to the increased incidence of birth trauma experienced by the preterm fetus. A common clinical misconception is that molding is induced by the maternal bony pelvis. If the bony pelvis was the sole cause of molding, then the preterm head would pass more easily through the birth canal. However, the lower uterine segment (viz. the cervix) is capable of significantly molding the head. The intrauterine pressures are comparable in magnitude between preterm and term labors. Consequently, the preterm head with its weaker material properties may undergo significantly more deformation than its term counterpart.

Figures 7 and 8 indicate that the posterior portion of the parietal bone model crosses the sagittal plane and hence "overiaps" the opposite parietal bone. Such a condition is never observed clinically. This discrepancy is the result of the initial choice of boundary conditions for the model. The nodes which cross the symmetry plane are not restrained because they do not originally lie in that plane. Fixing each node as it reaches the plane of symmetry would require an incremental loading approach which is not justified for this initial study. Nevertheless, this apparent overlap does point out the restraining effect of the soft tissue joining these bones in the actual head.

The magnitudes and distributions of applied loads used in the models are representative (particularly for smaller degrees of dilatation) of normal vertex presentations with no complicating factors. Conditions which complicate vertex presentations, such as cephalopelvic disproportion or muscular spasm in the lower part of the cervix, dramatically increase the magnitude of the applied loads and possibly more important, they alter the distribution of these pressures. These changes are reflected in larger deformations of the bones and consequently of the enclosed brain.

\section{CONCLUSIONS}

The techniques of engineering structural analysis have been used to investigate the biomechanics of fetal head molding. While the modeling includes many simplifications and approximations, a number of observations can be made:

(1) Fetal cranial bone is a structure which is capable of deforming under load distributions typical of those found in normal labor.

(2) The small strains and stresses which the model predicts justifies the use of the linear finite element theory.

(3) Deformations in the model are qualitatively similar to those seen in radiographs of the fetal bead taken during labor.

(4) Preterm parietal bone is capable of undergoing 2-4 times the deformations of term parietal bone for the same load distribution.

Acknowledgements - This work was supported in part by funds from the Horace H. Rackham School of Graduate Studies, The Univervity of Michigan's Biomedical Research Support Grant, The University of Michigan's Medical School Fund for Computing and by grant HD11202 from the National Institutes of Health.

\section{REFERENCES}

Bathe, K., Wilson, E. L. and Peterson, F. E. (1974) SAP IV, a structural andysis program for static and dynamic re sponse of linear systems. University of California's Report No. EERC-11, Berkeley.

Baxter, J. (1946) Moulding of the foetal head: a comperisatory mechanism. J. Obstet. Gynaec. Br. Emp. 53, 212-218.

Bell, F. (1972) Biomechanics of human parturition. Ph.D. Thesis. The University of Strathclyde, Olasgow. 
Borell, U. and Fernstrom, I. (1958a) Die Umformung des kindlichen Kopfes während normaler Entbindungen in regeirechter Hinterhauptslage. Geburtsh Frauenheilk 18, 1156-1166.

Borell, U. and Fernstrom, 1. (1958b) Die Umformung des kindlichen Kopfes bei engem Becken. Geburtsh Frauenheilk 18, 1245-1256.

Churchill, J. A. (1970) Newborn cerebral trauma. Physical Trauma as an Etiological Agent in Mental Retardation. U.S. Department of Health, Education and Welfare, Washington.

Glenting, P. (1970) Etiology of Congenital Spastic Cerebral Palsy. F.A.D.L. s Forlag, Copenhagen.

Hellman, L. M. and Pritchard, J. A. (1970) William's Obstetrics, 14th Edn. Appleton-Century-Crofts, New York.

Holland, E. (1922) Cranial stress in the foetus during labour and on the effects of excessive stress on the intracranial contents: with an analysis of eighty-one cases of torn tentorium cerebelli and subdural cerebral hemorrhage. J. Obstet. Gynaec. Br. Emp. 29, 549-571.

Kriewall, T. J., Stys, S. J. and McPherson, G. K. (1977) Neonatal head shape after delivery : an index of molding. $J$. perinat: Med. 6, 260-267.

Lindgren, L. (1960) The causes of foetal head moulding in labour. Acta obstet. gynec. scand. 39, 46-62.

McElhaney, J. H., Fogle, J. L., Melvin, J. W., Haynes, R. R., Roberts, V. L. and Alem, N. M. (1970) Mechanical properties of cranial bone. J. Biomechanics 3, 495-512.
McPherson, G. K. and Kriewall, T. J. (1979) The elastic moduius of fetal cranial bone. J. Biomechanics 13, 9-16.

Moloy, H. C. (1942) Studies of head molding during labor. Am. J. Obstet. Gynec. 44, 762-782.

Scammon, R. E. and Calkins, L. A. (1929) The Development and Growth of the External Dimensions of the Human Body in the Fetal Period. University of Minnesota Press, Minneapolis.

Schwarcz, R. L., Strada-Saenz, G., Althabe, O., FernandesFunes, J., Alvarez, L. O. and Caldeyro-Bancia, R. (1970) Compression received by the head of the human fetus during labor. Physical Trauma as an Etiological Agent in Mental Retardation, Pp. 133-143. U.S. Department of Health, Education and Welfare, Washington.

Wigglesworth, J. S. and Husemeyer, R. P. (1977) Intercranial birth trauma in vaginal breech delivery: the continued importance of injury to the occipital bone. Br. J. Obstet. Gynaec. 84, 684-691.

Willerman, L. (1970a) Fetal head position during delivery, and intelligence. Physical Trauma as an Etiological Agent in Mental Retardation. pp. 105-108. U.S. Department of Health, Education and Welfare, Washington.

Willerman, L. (1970b) Maternal pelvic size and neuropsychological outcome. Physical Trauma as an Etiological Agent in Mental Retardation, pp. 109-112. U.S. Department of Health, Education and Welfare, Washington. 